УДК 582.475-145:581.112

doi: $10.31140 / j . v e s t n i k i b .2018 .1(203) .11$

\title{
ВОДНЫЙ ПОТЕНЦИАЛ АССИМИЛЯЦИОННОГО АППАРАТА ХВОЙНЫХ КАК МЕРА АКТИВНОСТИ И СОСТОЯНИЯ ВОДЫ В РАСТЕНИИ
}

\author{
С.Н. Сенькина \\ Федеральное государственное бюджетное учреждение науки \\ Институт биологии Коми научного чентра Уральского отделения РАН, Сыктывкар \\ E-mail: senkina@ib.komisc.ru
}

\begin{abstract}
Аннотация. Проведено сравнительное исследование водного потенциала в дневной и сезонной динамике хвои сосны и ели, произрастающих в условиях достаточного почвенного увлажнения в средней подзоне тайги Республики Коми. Выявлены диапазоны изменчивости данного показателя в течение нескольких вегетационных периодов и получены их средние значения. Показаны изменения водного потенциала в связи с возрастом хвои и произрастанием ее в разных частях кроны. Установлены зависимости водного потенциала хвои от климатических факторов и условий среды обитания.
\end{abstract}

Ключевые слова: Республика Коми, средняя подзона тайги, Picea obovata, Pinus sylvestris, хвоя, водный потенциал

\section{Введение}

Проблема глобального изменения климата является в настоящее время одной из актуальных и обсуждаемых в различных сферах научных исследований. C нарастанием избыточного увлажнения и ухудшением аэрации почв в ряду растительных сообществ изменяются характеристики водного режима растений, упрощается структура фитоценозов, уменьшается численность и видовое разнообразие популяций, снижается продуктивность древостоев (Абражко, 1981; The response..., 2002; Global climate..., 2010). Для оценки устойчивости гидрологического цикла лесных экосистем к колебаниям климата необходимо всестороннее изучение характеристик водного обмена растений, таких как интенсивность транспирации, оводненность, водный дефицит, водный потенциал. Чем шире амплитуда колебаний того или иного показателя, тем более приспособлен организм растения к условиям среды. Благодаря циркуляции внутренней влаги обеспечивается общая взаимосвязь всех физиологических процессов и функционирование организма как единого целого (Водный обмен..., 1989). Водный потенциал является силой, с которой растение удерживает влагу и служит показателем активности воды в нем, что способствует пониманию причин, вызывающих движение воды в системе почварастение-атмосфера. Вода движется через растение по градиенту водного потенциала, и чем он круче, тем быстрее поток воды (Богатырев, 2002). Высокая чувствительность этого показателя к незначительным изменениям в содержании воды дает возможность использовать его для оценки недостатка или избытка влаги в растении. У большинства древесных растений в условиях достаточного почвенного увлажнения устьица закрываются при водном потенциале в диапазоне от -1.5 до -3.0 МПа. В таежной зоне его величина в хвое ели может варьировать от -1.5 до -3.5 МПа (Варлагин, 1993; Веретенников, 2002; Физиология растений, 2008). Установлено, что критические (суб- летальные) величины этого показателя для хвойных пород в летнее время составляют от -5.0 до -7.5 МПа, для хвои ели они могут достигать -5.0... -6.0 МПа и более низких значений (Chien-Ren $\mathrm{Chu}, 1935$ (1936); Богатырев, 1985, 1986). В целом водный потенциал служит обратным показателем по отношению к активности воды и интенсивности транспирации, его уменьшение, сопровождаемое возрастанием водного дефицита, может привести к задержке роста растения (Слейчер, 1970; Oertli, 1976).

Цель настоящей работы заключалась в оценке показателя водного потенциала хвои сосны и ели для возможности использования его в качестве индикатора активности и состояния воды в растении.

\section{Материал и методы}

Наблюдения за динамикой водного потенциала хвои сосны обыкновенной (Pinus sylvestris L.) и ели сибирской (Picea obovata Ledeb.) проводили на территории Чернамского и Ляльского стационаров, расположенных в Усть-Вымском и Княжпогостском районах Республики Коми в средней подзоне тайги. Первичное таксационное описание древостоев проводили в период закладки пробных площадей (1980-1990-е гг.) с последующим перечетом через каждые 5-10 лет. Таксационные характеристики изученных древостоев приведены в табл. 1. В сосняке черничном влажном исследования проводили в 1982-1983 гг., сосновоеловом черничном - в 1981-1983 гг., ельнике черничном - в 1994-1995 и 2003 гг., лиственно-еловом чернично-разнотравном - в 1990 и 1992 1993 гг., ельнике черничном влажном - в 2002 , 2005,2012 гг. и в ельнике черничном сфагновом - в 2003-2008, 2012-2013 гг. Режимные наблюдения, связанные с изменениями показателя водного потенциала в разных частях кроны и в зависимости от возраста хвои, проводили в сосняке черничном влажном, сосново-еловом черничном, ельнике черничном влажном, ельнике 
Таксационные характеристики экспериментальных участков

\begin{tabular}{|c|c|c|c|c|c|c|c|c|c|}
\hline Тип леса & $\begin{array}{c}\text { Состав } \\
\text { древ остоя }\end{array}$ & Порода & $\begin{array}{c}\text { Возраст, } \\
\text { лет }\end{array}$ & $\begin{array}{c}\text { Количество } \\
\text { деревьев, } \\
\text { экз./га } \\
\end{array}$ & Бонитет & Полнота & $\begin{array}{c}\text { Запас } \\
\text { древесины, } \\
\text { ма }^{3} / \text { a } \\
\end{array}$ & $\begin{array}{c}\text { Средний } \\
\text { диаметр, см }\end{array}$ & $\begin{array}{c}\text { Средняя } \\
\text { в ысота, м }\end{array}$ \\
\hline \multicolumn{10}{|c|}{ Чернамский стационар } \\
\hline $\begin{array}{l}\text { Сосняк черничный } \\
\text { в лажный }\end{array}$ & $9 \mathrm{C} 1 \mathrm{~B}$ & C & 60 & 1730 & III & 0.8 & 205 & 14 & 16 \\
\hline Соснов о-еловый & 8С2Б+E (1 ярус) & C & 60 & 3070 & III & 0.9 & 235 & 16 & 15 \\
\hline черничный & 6Е2С2Б (2 ярус) & $E$ & 70 & & IV & & & 8 & 9 \\
\hline \multicolumn{10}{|c|}{ Ляльский стационар } \\
\hline Ельник черничный & $4 \mathrm{E} 3 \mathrm{C} 2 \mathrm{Oc} 15+П x$ & $\begin{array}{c}E \\
C \\
\text { OC } \\
5 \\
\text { Пx }\end{array}$ & $\begin{array}{c}70-120 \\
90 \\
90 \\
40-90 \\
90\end{array}$ & 1849 & III & 0.9 & 293 & $\begin{array}{l}16 \\
21 \\
25 \\
10 \\
10\end{array}$ & $\begin{array}{l}16 \\
20 \\
21 \\
12 \\
11\end{array}$ \\
\hline $\begin{array}{l}\text { Лиственно-елов ый } \\
\text { чернично-разно- } \\
\text { трав ный }\end{array}$ & $50 c 451 C+E$ & $\begin{array}{l}\text { Oc } \\
\text { 5 } \\
\text { C } \\
\text { E }\end{array}$ & $\begin{array}{l}46 \\
45 \\
45 \\
40\end{array}$ & 1675 & II & 1.0 & 270 & $\begin{array}{l}18 \\
13 \\
17 \\
10\end{array}$ & $\begin{array}{l}20 \\
16 \\
17 \\
7\end{array}$ \\
\hline $\begin{array}{l}\text { Ельник черничный } \\
\text { влажный }\end{array}$ & $8 \mathrm{E} 1 \Pi \times 15+C$ & $\begin{array}{l}E \\
\text { Пx } \\
5 \\
C\end{array}$ & $\begin{array}{c}80-150 \\
100 \\
60-100 \\
100\end{array}$ & 966 & IV & 0.8 & 314 & $\begin{array}{l}22 \\
25 \\
12 \\
21\end{array}$ & $\begin{array}{l}19 \\
19 \\
17 \\
22\end{array}$ \\
\hline $\begin{array}{l}\text { Ельник чернично- } \\
\text { сфрагнов ый }\end{array}$ & 9E1Б+C ед.Пх & $\begin{array}{l}E \\
5 \\
C \\
\Pi x\end{array}$ & $\begin{array}{c}100-200 \\
110 \\
110 \\
50\end{array}$ & 625 & V & 0.8 & 194 & $\begin{array}{l}20 \\
32 \\
40 \\
10\end{array}$ & $\begin{array}{l}16 \\
23 \\
22 \\
10\end{array}$ \\
\hline
\end{tabular}

чернично-сфагновом (1981-1983 и 2002-2005 гг.). В зависимости от цели исследования, ветки срезали секатором из разных частей кроны, разного возраста хвои, времени суток и периода вегетации. Водный потенциал определяли компенсационным методом (Максимов, 1948) с помощью рефрактометра марки УРЛ (универсальный рефрактометр лабораторный типа Аббе отечественного производства). Готовили несколько растворов сахарозы разной концентрации, хвою измельчали и помещали в аптечные пузырьки таким образом, чтобы раствор полностью ее покрывал (12 мл), а затем плотно закрывали пробками. Каждый образец исследовали в трехкратной повторности. Через два часа вновь определяли концентрацию раствора. Считается, что если она не изменилась, то соответствует водному потенциалу хвои. Водный потенциал является отрицательной величиной, таким образом, чем этот показатель отрицательнее, тем он выше, выражали его в мегапаскалях (МПа). Полученные данные обрабатывали с помощью стандартных статистических методов (Лакин, 1980), используя компьютерные программы MS OFFICE EXCEL («Microsoft», CIIA) и STATISTICA («StatSoft Inc.», CШIA).

\section{Результаты и обсуждение}

Как показали проведенные исследования, средние значения водного потенциала хвои сосны в изученных фитоценозах в разные годы изменяются от -1.3 до $-1.6 \mathrm{MПа} \mathrm{в} \mathrm{хвое} \mathrm{первого} \mathrm{года}$ жизни и от -1.6 до $-1.8 \mathrm{MПа} \mathrm{в} \mathrm{хвое} \mathrm{второго} \mathrm{года}$ жизни. У хвои ели эти показатели находятся в пределах $-1.5 \ldots-1.7$ и $-2.0 \ldots-2.2$ МПа соответ- ственно. Амплитуда изменения данного показателя у ели в разные вегетационные сезоны шире, чем у сосны (табл. 2). В целом полученные нами результаты укладываются в диапазон величин водного потенциала, известных для хвойных пород таежной зоны (-1.5...-3.5 МПа) (Богатырев, 1985, 1986; Веретенников, 2002;). Для большинства растений нормальное протекание процессов жизнедеятельности возможно при водном потенциале, не превышающем -1.5...-2.0 МПа. У хвои сосны первого года наибольшие значения водного потенциала выявлены в ельнике черничном, в хвое второго года - в сосняке черничном. У ели для хвои как первого, так и второго годов жизни наибольший водный потенциал отмечен в ельнике чернично-сфагновом. Согласно данным других исследователей, величина водного потенциала хвои сосны в черничном типе леса в Тверской области составила -1.2 МПа, ели -2.2 МПа (Варлагин, 2000). В сосняках черничных Белоруссии в хвое сосны значение показателя составило -1.8 , хвое ели -2.2 МПа (Гаранович, 1972), в Карелии $-0.7 \ldots-1.6$ и $-1.1 \ldots-2.5$ МПА соответственно (Сазонова, 2005, 2008). На характер водообмена в хвойных фитоценозах существенно влияют как метеоусловия (солнечная радиация, температура и влажность воздуха), так и температура почвы и запасы влаги в ней. Взаимовлияние внешних условий и внутренних факторов регулирования водообмена растений выявляются не только в тех случаях, когда запас воды в почве минимальный, но и при достаточном водоснабжении (Абражко, 1998). В исследуемых древостоях преобладают подзолистые почвы. Гидротермические свойства 
Водный потенциал хвои сосны и ели в разных типах леса, МПа

Таблица 2

\begin{tabular}{|c|c|c|c|c|c|c|}
\hline \multirow{2}{*}{ Тип леса } & \multicolumn{3}{|c|}{ Хвоя первого года жизни } & \multicolumn{3}{|c|}{ Хвоя второго года жизни } \\
\hline & $\mathrm{n}$ & $\mathrm{M} \pm \mathrm{m}$ & $\mathrm{t}$ & $\mathrm{n}$ & $\mathrm{M} \pm \mathrm{m}$ & $\mathrm{t}$ \\
\hline \multicolumn{7}{|c|}{ Сосна } \\
\hline \multirow[t]{2}{*}{ Сосняк черничный влажный } & 51 & $\begin{array}{l}-1.5 \pm 0.6 / \\
-2.0 \ldots-1.2\end{array}$ & & 51 & $\begin{array}{r}1.6 \pm 0.07 / \\
-2.1 \ldots-1.3\end{array}$ & \\
\hline & & & 1.25 & & & $2.0^{\star}$ \\
\hline \multirow[t]{2}{*}{ Сосново-еловый черничный } & 51 & $\begin{array}{l}-1.6 \pm 0.06 / \\
-2.1 \ldots-1.2\end{array}$ & & 51 & $\begin{array}{l}-1.8 \pm 0.08 / \\
-2.6 \ldots-1.3\end{array}$ & \\
\hline & & & $3.75^{*}$ & & & 1.25 \\
\hline \multirow[t]{2}{*}{ Ельник черничный } & 40 & $\begin{array}{l}-1.3 \pm 0.06 / \\
-1.5 \ldots-1.2\end{array}$ & & 40 & $\begin{array}{l}-1.7 \pm 0.01 / \\
-1.9 \ldots-1.5\end{array}$ & \\
\hline & & Ель & & & & \\
\hline \multirow[t]{2}{*}{ Сосново-еловый черничный } & 20 & $\begin{array}{l}-1.7 \pm 0.08 / \\
-2.2 \ldots-1.4\end{array}$ & & 30 & $\begin{array}{c}-2.7 \pm 0.09 / \\
2.7 .-1.4\end{array}$ & \\
\hline & & & 0 & & & $3.12^{*}$ \\
\hline \multirow[t]{2}{*}{$\begin{array}{l}\text { Лиственно-еловый } \\
\text { чернично-разнотравный }\end{array}$} & 35 & $\begin{array}{l}-1.7 \pm 0.24 / \\
-2.4 \ldots-1.2\end{array}$ & & 30 & $\begin{array}{l}-2.2 \pm 0.13 / \\
-2.6 \ldots-2.0\end{array}$ & \\
\hline & & & 0.4 & & & 0.75 \\
\hline \multirow[t]{2}{*}{ Ельник черничный влажный } & 39 & $\begin{array}{l}-1.6 \pm 0.05 / \\
-1.7 \ldots-1.4\end{array}$ & & 60 & $\begin{array}{l}-2.0 \pm 0.07 / \\
-2.2 \ldots-1.7\end{array}$ & \\
\hline & & & 0.5 & & & 0 \\
\hline Ельник чернично-сфрагновый & 67 & $\begin{array}{l}-1.5 \pm 0.14 / \\
-2.4 \ldots-1.0\end{array}$ & & 84 & $\begin{array}{l}-2.0 \pm 0.06 / \\
-2.4 \ldots-1.8\end{array}$ & \\
\hline
\end{tabular}

Примечания: $\mathrm{n}$ - число наблюдений; М - среднее значение; m - средняя квадратичная ошибка, в числителе средние значения, в знаменателе - диапазон изменений; $\mathrm{t}$ - критерий достоверности; * различия показателей водного потенциала достоверны при уровне значимости $\mathrm{P} \geq 0.05$. Сроки исследований в каждом типе леса приведены в разделе «Материал и методы».

почв обеспечивают активную жизнедеятельность корней в верхнем слое (60 см). Влагозапасы теплого периода держатся в доступной форме. В верхней части этой толщи период с температурой $+10{ }^{\circ} \mathrm{C}$ и более составляет 1.5-2.5 месяца, в нижней - менее одного месяца (Забоева, 2001). Близкие значения водного потенциала в диапазоне $-1.3 . .-2.5 \mathrm{MПа} \mathrm{в} \mathrm{условиях} \mathrm{достаточного} \mathrm{почвен-}$ ного увлажнения приводят и другие исследователи (Гаранович, 1972; Взнуздаев, 1973; Сазонова, 1982). Нами было отмечено ранее (Сенькина, 2013), что как интенсивность транспирации, так и водный потенциал хвои сосны и ели тесно связаны с изменениями метеофакторов как в дневной, так и в сезонной динамике. Как отмечет Hetsch (1981), в условиях нормального увлажнения почвы водный потенциал деревьев в большей степени зависит от влажности воздуха. При снижении степени насыщения воздуха газообразной водой потенциал быстро понижается (Варлагин, 1993; Физиология растений, 2008; Sellin, 2016). Было выявлено, что при относительной влажности воздуха ниже $33 \%$ у сосны и $31 \%$ у ели и температуре воздуха выше $25{ }^{\circ} \mathrm{C}$ водный потенциал хвои увеличивается. Исходя из генеральной выборки для обоих видов деревьев выявлена обратная корреляция между влажностью воздуха и величиной водного потенциала хвои (для сосны $\mathrm{R}=-0.8 \pm 0.2$, для ели $\mathrm{R}=-0.5 \pm$ 0.1) (Сенькина, 2013). Вода всегда поступает в сторону более отрицательного водного потенциала. Атмосфера обычно не насыщена водяными парами, поэтому обладает самым низким водным потенциалом. При нормальном атмосферном давлении (0.1 МПа, или 760 мм рт. ст.) и температуре воздуха $25{ }^{\circ} \mathrm{C}$ водный потенциал чистой воды максимален и равен 0. У любых водных растворов потенциал всегда ниже, чем у чистой воды. Так, при относительной влажности воздуха 90\% водный потенциал равен -14 МПа. При пониженной влажности воздуха он уменьшается благодаря изменениям ширины устричной щели (Варлагин, 1993). Во влажные годы, когда месячная сумма осадков больше среднемноголетней нормы, а средняя температура воздуха меньше среднемноголетней нормы, значения показателя находятся у хвои сосны в диапазоне $-1.7 \ldots-2.0 \mathrm{MПа,}$ у хвои ели $-1.6 \ldots-2.1$ МПа. В более засушливые годы, когда сумма осадков меньше, а температура воздуха выше среднемноголетних норм, эти показатели составляют $-1.5 \ldots-1.7$ и $-1.5 \ldots-2.5$ МПа соответственно. Повышение величин водного потенциала обычно сопровождается возрастанием водного дефицита. Высокий водный потенциал и большой водный дефицит приводят к активизации поглощения воды корнями, но не всегда увеличивают интенсивность транспирации. У ели по сравнению с сосной отмечается более тесная положительная корреляция между водным потенциалом и водным дефицитом $(\mathrm{R}=0.6 \pm 0.1$ 
и $\mathrm{R}=0.4 \pm 0.1$ соответственно). Между интенсивностью транспирации и водным потенциалом нами была зафиксирована средняя связь (от 0.5 до 0.7). Не отмечено и тесной связи водного потенциала с температурой воздуха: у сосны коэффициент корреляции составил $0.08 \pm 0.01$, а для ели он оказался даже отрицательным $(-0.3 \pm$ 0.04). Специальных исследований по зависимости водного потенциала от интенсивности освещения нами не проводилось, но вполне очевидно, что от потери влаги деревом и повышения водного дефицита возникает потребность в возмещении потерянной влаги. В литературе имеются сведения, что в еловых древостоях южной тайги наблюдается тесная связь водного потенциала с освещенностью и что водный потенциал ели увеличивается при более низкой освещенности, тем у сосны (Абражжко, 1975; Сазонова, 2005; 2008).

Водный потенциал находится в обратной зависимости от содержания свободной воды. В течение вегетационного сезона он может изменяться в широком диапазоне. В исследуемых древостоях в сформировавшейся хвое второго года как у сосны, так и у ели этого не наблюдали. В хвое первого года жизни водный потенциал меняе'ся с июня по сентябрь на 0.5 МПа. По некоторым данным (Погодаева, 1975), минимальный водный потенциал отмечается в конце вегетации, когда в листьях уменьшается количество влаги. Понижение водного потенциала указывает на превышение водорасхода над водопотреблением, чаще всего это происходит за счет увеличения интенсивности транспирации и водного дефицита хвои, что наблюдается не только летом, но и весной за счет того, что весной, когда устанавливается плюсовая температура воздуха, дерево начинает транспирировать, в это время почва еще недостаточно прогрета, поэтому всасывание воды корнями затруднено. Вариабельность водного потенциала хвои ели первого-третьего года в течение вегетационного сезона составляет $23 \%$, хвои сосны $-17 \%$.

Анализ дневной динамики водного потенциала показал, что с нарастанием температуры воздуха (25-30 $\left.{ }^{\circ} \mathrm{C}\right)$ с 11 до 13 ч, снижением относи-

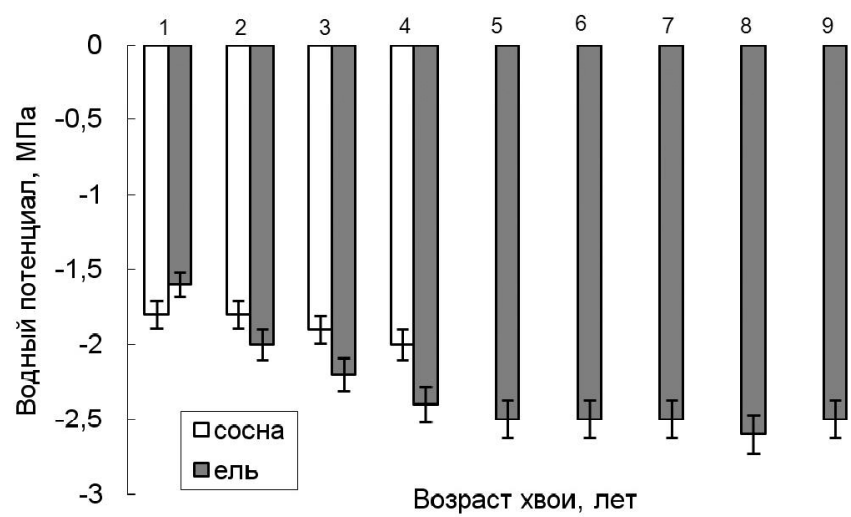

Водный потенциал хвои разного возраста сосны и ели. тельной влажности воздуха (40-50\%) с 12 до 13 ч и высокой освещенности в этот период (до 60000 лк) водный потенциал достигает минимальных значений $(-1.0 \ldots-1.2$ МПа). В ранние утренние часы он составляет $-0.2 \ldots-0.3$ МПа. В исследуемых древостоях водный потенциал в дневное время суток в разные годы исследований в разных типах леса колеблется от -1.6 до -1.9 МПа у сосны и от -1.8 до -2.2 МПа у ели. В ночное время водный запас растения восполняется и происходит увеличение водного потенциала. В это время у них наблюдается минимальный водный дефицит. Утром с увеличением температуры и уменьшением относительной влажности воздуха расход влаги увеличивается и водный потенциал уменьшается. Такая же дневная динамика водного потенциала выявлена для условий северозапада России (Сазонова, 2007, 2015). Изменения водного потенциала в течение суток связаны прежде всего с колебаниями погодных условий, так как почвенная влагообеспеченность растений достаточная. Исследования водного обмена на фоне изменяющихся факторов внешней среды позволяют оценить адаптивные возможности сосны и ели в широком диапазоне внешних условий.

Одним из адан'ационных признаков хвойных растений к условиям произрастания на Севере служит продолжительность жизни хвои, которая достигает 8 лет для сосны и 13 лет для ели, что позволяет этим растениям активнее продуцировать и накапливать биологическую массу в течение короткого периода вегетации. Нами была прослежена динамика изменения водного потенциала в хвое сосны первого-четвертого года жизни и хвое ели с первого по девятый год (см. рисунок). У ели наибольший водный потенциал отмечен в хвое первого года жизни (-1.6 МПа), затем он снижается до $-2.5 \mathrm{MПа} \mathrm{в} \mathrm{девятилетней} \mathrm{хвое.}$ В хвое сосны не отмечено большой разницы в величине водного потенциала с увеличением возраста хвои. Как правило, хвоя первого года жизни по сравнению с хвоей старших возрастов более обводнена и имеет меньший водный дефицит, поэтому водный потенциал молодой хвои ниже, чем хвои последующих возрастов, т.е. по мере старения хвои он повышается. Водный потенциал хвои сосны первого года жизни колеблется от -1.3 до -2.8 МПа, хвои второго-третьего года жизни от -1.3 до -2.9 МПа. При этом наибольшее количество показаний водного потенциала как в хвое первого года, так и в последующих возрастах приходится на -1.3 МПа. У хвои ели диапазон варьирования находится в пределах $-1.3 \ldots-2.5$ и $-1.7 \ldots-2.7$ МПа соответственно. В хвое первого года наибольшее количество данных соответствует $-1.4 \mathrm{MПа,} \mathrm{в} \mathrm{старших} \mathrm{возрас-}$ тах -2.0 МПа.

Хвоя разных ярусов кроны у одних и тех же растений находится в неодинаковых условиях водоснабжения. Поступление воды в верхние ча- 
сти кроны обусловлено преодолением большого сопротивления. Кроме того, хвоя в кроне деревьев находится в неравноценных микроклиматических условиях. В верхней и нижней ее частях установлены разные значения освещенности, влажности, температуры воздуха (Fitter, 2002). В разных типах древостоев отмечена различная динамика водного потенциала по частям кроны, что объясняется разной высотой деревьев и протяженностью кроны по стволу (Цельникер, 2000). Так, у ели протяженность кроны от нижней части к верхней превышает таковую у сосны. Соответственно водный потенциал хвои ели по длине кроны варьирует в пределах $27 \%$, хвои сосны 18\% . Еще В.Р. Заленским (1904) установлено, что более высоко расположенные листья растений часто попадают в условия худшего водоснабжения, но при этом они отличаются и более высокой интенсивностью транспирации, так как устьица у листьев верхних ярусов даже при водном дефиците дольше остаются открытыми. В пределах полога кроны водный потенциал хвои ели возрастает от нижней части кроны к верхней в среднем от -3.0 до -2.2 МПа. У сосны отмечается противоположная динамика изменения этого показателя, он уменьшае'ся о'т нижней час'ти кроны к верхней в среднем от -1.4 до -1.7 МПа.

\section{Заключение}

Многолетние исследования водного потенциала хвои сосны и ели в разных типах леса позволили установить, что в условиях достаточного почвенного увлажнения диапазон изменчивости параметров водного потенциала в течение разных вегетационных периодов у ели в 1.2 раза шире, чем у сосны как в хвое первого года жизни, так и в сформировавшейся двухлетней хвое. Широкая амплитуда водного потенциала хвои ели позволяет сделать вывод о том, что данная порода имеет большие преимущества в приспособлении к новым условиям существования. У хвои сосны наибольшие значения этого показателя выявлены в ельнике и сосняке черничном, у ели - в ельнике чернично-срагновом. Диапазон средних значений водного потенциала исследуемых видов деревьев значительно ниже сублетальных значений (-5.0/-7.5 МПа). В исследуемых условиях водный потенциал у обеих пород в значительной степени зависит от влажности воздуха (для сосны $\mathrm{R}=-0.8 \pm 0.2$, для ели $\mathrm{R}=-0.5 \pm 0.1$ ). Повышение величины водного потенциала сопровождается возрастанием водного дефицита, что более выражено у ели, чем у сосны. В течение вегетационного периода с июня по сентябрь он изменяется незначительно, в пределах 0.5 МПа. Изменения данного показателя в дневное время обусловлены суточным ходом метеофакторов. Анализ дневной динамики показал, что в полуденные часы с нарастанием температуры и снижением влажности воздуха, а также высокой интен- сивностью света водный потенциал достигает минимальных значений (-1.0..-1.2 МПа). Установлено, что этот показатель является инвариантным, т.е. величина его незначительно варьирует в разные вегетационные периоды. С возрастом хвои водный потенциал ели снижается с -1.6 до -2.5 МПа, в то время как у сосны отмечены незначительные изменения и по вертикальному профилю кроны, что связано как с протяженностью кроны по стволу дерева, так и с преодолением большого сопротивления при поступлении воды в верхнюю ее часть. Немаловажную роль играет и создающийся в пределах кроны микроклимат.

\section{ЛИТЕРАТУРА}

Абражко, В. И. Водный режим сообществ еловых лесов : автореф. дис. ... докт. биол. наук / В. И. Абражко. - Санкт-Петербург, 1998. - 46 с.

Абражко, В. И. Водный стресс и стабильность древостоев // Всесоюзное совещание по вопросам адаптации древесных растений к экстремальным условиям среды : тезисы докладов. - Петрозаводск, 1981. - С. 89.

Абражко, В. И. О некоторых особенностях водного режима еловых древостоев южной тайги / В. И. Абражко, М. А. Абражко // Водный обмен в основных типах растительности СССР. - Новосибирск : Наука, 1975. - C. $75-79$.

Богатырев, Ю. Г. Водный режим почвы и подроста ели на вырубках и под пологом / Ю. Г. Богатырев, И. Н. Васильева // Лесоведение. - 1985. - № 2. - С. $16-25$.

Богатырев, Ю. Г. О возможности измерения полного водного потенциала растений камерой давления // Лесоведение. - 2002. - № 1. - С. 52-57.

Богатырев, Ю. Г. Роль водного режима в напряженности жизненных процессов саженцев ели европейской / Ю. Г. Богатырев, И. Н. Васильева // Лесоведение. - 1986. - № 2. - С. 76-80.

Варлагин, А. В. Влияние эколого-морфологических факторов на устьичное сопротивление ели европейской / А. В. Варлагин, Н. И. Выгодская // Лесоведение. - 1993. - № 3. - С. 48-60.

Варлагин, А. В. Транспирация на уровне листа, дерева и сообщества в хвойных лесах : автореф. дис. ... канд. биол. наук / А. В. Варлагин. - Москва, 2000. 37 c.

Веретенников, А. В. Физиология растений / А. В. Веретенников. - Воронеж : Воронежская государственная лесотехническая академия, 2002. - 272 с.

Взнуздаев, Н. А. Определение потенциала влаги в системе почва-растение / Н. А. Взнуздаев // Проблемы лесного почвоведения. - Москва : Наука, 1973. C. $83-92$.

Водный обмен растений / под ред. И. А. Тарчевского, В. Н. Жолкевича. - Москва : Наука, 1989. 256 с.

Водный режим древесных растений в условиях достаточного почвенного увлажнения на северо-западе России / Т. А. Сазонова, И. Н. Софронова, Е. В. Новичонок, В. Б. Придача // Международный журнал прикладных и фундаментальных исследований. - 2015. № 8. - С. 299-302.

Гаранович, И. М. Сосущая сила и интенсивность транспирации некоторых видов растений в различных типах соснового леса / И. М. Гаранович // Ботаника. - Минск : Наука и техника, 1972. - Вып. 14. C. 214-217. 
Забоева, И. В. Почвенно-экологические условия еловых сообществ / И. В. Забоева // Биопродукционный процесс в лесных экосистемах Севера. - СанктПетербург : Наука, 2001. - С. 112-131.

Заленский, В. Р. Материалы к количественной анатомии различных листьев одних и тех же растений / В. Р. Зеленский // Известия Киевского политехнического института. -1904. - Т. 4, кн. 1. - 112 с.

Физиология растений / П. Заме, Э. В. Вайлер, И. В. Казерайт, К. Кернер // Ботаника. - Москва : Издательский центр "Академия", 2008. - Т. 2. - 496 с.

Лакин, Г. Ф. Биометрия / Г. Ф. Лакин. - Москва : Высшая школа, 1980. - 293 с.

Максимов, Н. А. Определение сосущей силы листьев методом компенсации с помощью рефрактометpa / Н. А. Максимов, Н. С. Петинов // Доклады АН CCCP. - 1948. - Т. 62, № 4. - С. 537-540.

Погодаева, Н. Н. Расход воды на транспирацию лесными и кустарниковыми сообществами в районе Ивано-Арахлейских озер (Читинская обл) : автореф. дис. ... канд. биол. наук / Н. Н. Погодаева. - Иркутск, 1975. - 26 с.

Сазонова, Т. А. Динамика потребления влаги средневозрастным сосновым насаждением : автореф. дис ... канд. биол. наук / Т. А. Сазонова. - Красноярск, 1982. - 26 с.

Сазонова, Т. А. Влияние факторов внешней среды на показатели водного обмена Pinus sylvestris, Picea abies и Betula pendula / Т. А. Сазонова, С. В. Колосова // Ботанический журнал. - 2005. - Т. 90, № 8. C. 1227-1235.

Сазонова, Т. А. Водный режим Pinus sylvestris и Picea obovata (Pinaceae) в условиях промышленного загрязнения / Т. А. Сазонова, С. В. Колосова, Л. Г. Исаева // Ботанический журнал. - 2007. - Т. 92, № 5. C. 740-750.

Сазонова, Т. А. Жизнедеятельность хвойных растений в условиях северо-запада России / Т. А. Сазонова, В. Б. Придача // Фундаментальные и прикладные проблемы ботаники в начале XXI в. - Петрозаводск, 2008. - C. 102-103.
Сенькина, С. Н. Водный режим сосны и ели в фитоценозах Севера / С. Н. Сенькина. - Екатеринбург : РИО УрО РАН, 2013. - 104 с.

Слейчер, Р. Водный режим растений / Р. Слейчер. Москва : Мир, 1970. - 365 с.

Цельникер, Ю. Л. Морфологические и физиологические исследования кроны деревьев / Ю. Л. Цельникер, М. Д. Корзухин, Б. Б. Зейде. - Москва : Мир, 2000. - 93 c.

Chien-Ren Chu. Der Einfluss des Wassergehaltes der Blatter der Waldbaume aif thre Lebensfahigkeit, ihre Saugkrafte und ihren Turgor / Chien-Ren Chu // Flora, 1935 (1936). - Bd. 30 (130). - S. 84-437.

Fitter, A. H. Environmental physiology of plants / A. H. Fitter, R. K. V. Hay. - San Diego : Acad. Press, 2002. -367 p.

Global climate change and trr nutrition: effects of elevated $\mathrm{CO}_{2}$ and temperature / M. Lukas, C. Calfapietra, F. Lagomarsino, F. Loreto // Tree physiology. - 2010. Vol. 30, N 9. - P. 1209-1220.

Growth of northern deci duous trees under increasing atmospheric humidity: possible mechanisms behind the growth retardation / A. Sellin, M. Alber, M. Keinanen, P. Kupper, J. Lihavainen, K. Lohmus, E. Oksanen, A. Sober, J. Sober, A. Tullus // Regional Environmental Change. - 2016. - P. 1-14.

Hetsch, W. Wasserhaushalt von Fichte in Abhangigkeit von Boden und Atmosphare / W. Hetsch, K.-H. Heilig // Journal of Plant Nutrion and Soil Science. 1981. - Vol. 144, iss. 3. - P. 317-330.

Oertli, J. J. The soil-plant-atmochere continuum / J. J. Oertli // Water and plant life. - N.-Y., 1976. P. 3-20.

The response of the water fluxes of the boreal forest region at the Volga's source area to climatic and landuse changes / A. Oltchev, J. Chermak, J. Gurtz, G. Kiely, N. Nadezhdina, A. Tishenko, M. Zappa, N. Lebedeva, T. Vitvar, J.D. Albertson, F. Tatarinov, D. Tishenko, V. Nadezhdin, B. Kozlov, A. Ibrom, N. Vygodskaya, G. Gravenhorst // J. Phys. Chem. Earth - 2002. - Vol. 27, N 9. - P. 675-690.

\title{
WATER POTENTIAL OF THE ASSIMILATION APPARATUS OF CONIFEROUS AS THE MEASURE OF WATER ACTIVITY AND CONDITION OF IN THE PLANT
}

\author{
S.N. Senkina
}

Institute of Biology of Komi Scientific Centre of the Ural Branch of the Russian Academy of Sciences, Syktyvkar

Summary. In the studied coniferous phytocoenoses, mean values of water potential in needles varied from -1.3 to $-1.6 \mathrm{MPa}$ for pine needles of the first year age and from -1.6 to $-1.8 \mathrm{MPa}$ for the second year age and from -1.5 to -1.7 and from -2.0 to $-2.2 \mathrm{MPa}$ for spruce needles, respectively. Needle water potential increased at relative air humidity below $33 \%$ for pine and $31 \%$ for spruce and air temperature above $25{ }^{\circ} \mathrm{C}$. Negative dependence was found between the air humidity and the water potential of both species under study. In years with high precipitation, water potential varied from -1.7 to $-2.0 \mathrm{MPa}$ for pine needles and $-1.6 \ldots-2.1 \mathrm{MPa}$ for spruce needles. In more arid years, it varied from -1.5 to -1.7 and $-1.5 \ldots-2.5 \mathrm{MPa}$ respectively. The decrease in water potential indicates the excess of water intake over water outgo. This fact is often due to an increase in the intensity of transpiration and needle water deficiency, which is observed not only in summer, but also in spring. In the studied stands, water potential of pine needles varied from -1.6 to $-1.9 \mathrm{MPa}$ during the day, for spruce - from -1.8 to $-2.2 \mathrm{MPa}$. The highest value of water potential was recorded in the needles of the first year age, and then it decreased. Needles from different levels of the crown of the same trees are in different conditions of water supply. For spruce, water potential of needles along the length of the crown changed by $27 \%$, for pine - by $18 \%$. Within the canopy of the crown, water potential of spruce needles increased from the lower part of the crown to the top. Pine had the opposite dynamics of this index; it decreased from the lower part of the crown to the top.

Key words: Komi Republic, middle taiga, Picea obovata, Pinus sylvestris, needles, water potential 